\title{
Working memory in multilingual children: Is there a bilingual effect?
}

\author{
Pascale M. J. Engel de Abreu
}

Educational Measurement and Applied Cognitive Science Research Unit, University of Luxembourg/Luxembourg

This is the author's copy of the article. The definitive version has been published in Memory (2011). Content may

be protected by copyright law and subject to the fair use doctrine. You agree to use the information therein solely for academic research and promise to adhere to all applicable copyright restrictions.

\begin{abstract}
This research investigates whether early childhood bilingualism affects working memory performance in 6- to 8-year-olds, followed over a longitudinal period of three years. The study tests the hypothesis that bilinguals might exhibit more efficient working memory abilities than monolinguals, potentially via the opportunity a bilingual environment provides to train cognitive control by combating interference and intrusions from the non-target language. Forty-four bilingual and monolingual children, matched on age, sex, and socioeconomic status, completed assessments of working memory (simple span and complex span tasks), fluid intelligence, and language (vocabulary and syntax). The data showed that the monolinguals performed significantly better on the language measures across the years whereas no language group effect emerged on the working memory and fluid intelligence tasks after verbal abilities were considered. The study suggests that the need to manage several language systems in the bilingual mind affects children's language skills whilst having little impact on the development of working memory abilities.
\end{abstract}

Keywords: bilingualism; working memory; cognitive control; fluid intelligence; language.

The bilingual effect has been referred to as the task performance discrepancy among bilinguals and monolinguals on a range of cognitive measures. Whereas bilinguals are generally found to underperform on standardized vocabulary assessments, they have been shown to outperform their monolingual peers on a variety of executive control tasks (see Bialystok, 2001, for a review). Whether bilingualism affects working memory is currently unclear. The major aim of this study was to explore working memory task performance in young bilingual and monolingual children growing up in Luxembourg to determine if a bilingual advantage exists and how it might develop over time.

Considerable evidence has accumulated suggesting that bilinguals, that is individuals who use several languages in their everyday lives (Grosjean, 2010), activate all of their languages in parallel during speech production (Costa, Roelstraete, \& Hartsuiker, 2006; Jared \& Kroll, 2001; Van Hell \& Dijkstra, 2002). This joint activation of several language systems in the bilingual mind creates lexical conflict between competing responses. It has been argued that mechanisms of cognitive control are needed to resolve this conflict by maintaining activation of the relevant language in addition to suppressing interference from the nontarget language (Bialystok, 1999; Ursino, Cuppini, \& Magosso, 2010). In the light of increasing neuropsy- chological evidence demonstrating that the human brain adapts to repeated activity and environmental experience (Jaeggi, Buschkuehl, Jonides, \& Perrig, 2008; Klingberg, Forssberg, \& Westerberg, 2002), it has been suggested that the constant use of cognitive control to resolve linguistic conflict may boost performance on tasks that rely on this particular mechanism. Indeed, fluent bilinguals who need to flexibly switch between languages on a regular basis, have been found to outperform monolinguals on a range of inhibition tasks involving interference suppression (Bialystok, Craik, \& Luk, 2008; Bialystok, Craik, \& Ryan, 2006; Carlson \& Meltzoff, 2008; Martin-Rhee \& Bialystok, 2008). Bilinguals have also been found to perform significantly better than monolinguals on measures of task switching (Bialystok \& Martin, 2004; Carlson \& Meltzoff, 2008). In contrast, on standardized measures of vocabulary young bilinguals frequently perform at lower levels than their monolingual peers, especially if only one of their languages is considered (Carlson \& Meltzoff, 2008; Namazi \& Thordardottir, 2010; Pearson, Fernández, \& Oller, 1995; Thordardottir, Rothenberg, Rivard, \& Naves, 2006).

One important cognitive mechanism that has been consistently linked to cognitive control is working memory. Working memory refers to a system that is required to maintain information in an accessible state 
in the face of concurrent processing, distraction, and/or attention shifts (Baddeley \& Hitch, 1974; Conway, Cowan, Bunting, Therriault, \& Minkoff, 2002; Engle, Tuholski, Laughlin, \& Conway, 1999). A large body of research findings has shown that scores on assessments of working memory are strongly related to language learning in both native and foreign languages (Engel, 2009; Majerus, Poncelet, Greffe, \& Van der Linden, 2006; Masoura \& Gathercole, 2005; Service, 2006) leading to the hypothesis that working memory might have evolved in humans as a "language learning device" (Baddeley, Gathercole, \& Papagno, 1998). The working memory system is generally assessed by simple span tasks that require the maintenance of information over a short period of time and by complex span tasks that, in addition to storage, also involve an explicit concurrent processing task. It is now widely accepted that working memory comprises of mechanisms devoted to the short-term storage of information and domain-general mechanisms of cognitive control that regulate and coordinate those maintenance operations and prevent working memory overload by suppressing activated task-irrelevant information (Baddeley, 2000; Cowan et al., 2005; Engle, 2010; Engle et al., 1999). In a series of studies on adults, Engle and colleagues have shown that individuals who perform better on complex span tasks are also more proficient in proactive interference (Bunting, 2006; Kane \& Engle, 2000; Unsworth \& Engle, 2007). Developmental research indicates that children with lower working memory spans are less able than high span individuals to inhibit a previously activated rule or response set (Epsy \& Bull, 2005). Furthermore, cognitive control has been identified as the key mechanism underlying the link between working memory and fluid intelligence in both children and adults (Conway et al., 2002; Engel de Abreu, Conway, \& Gathercole, 2010; Engle et al., 1999).

There has been little research investigating working memory in bilinguals. The few studies that do exist provide mixed results with some studies demonstrating a bilingual benefit (Bialystok, Craik, Klein, \& Viswanathan, 2004) and others finding no such effect (Bajo, Padilla, \& Padilla, 2000; Bialystok, Craik \& Luk, 2008; Namazi \& Thordardottir, 2010). One possibility is that bilingual experience might affect working memory performance through its impact on cognitive control. In this respect, it is possible that bilinguals may exhibit more efficient working memory abilities than monolinguals potentially via the opportunity that a bilingual environment provides in training cognitive control by inhibiting one language system whilst the other is being used in addition to combating interference and intrusions from the non-target language.

The presented study directly tests this hypothesis by administrating a range of complex and simple working memory span tasks to both bilingual and monolingual children from the Grand-Duchy of Luxembourg. Although the Grand-Duchy is officially trilingual - with Luxembourgish, German, and French being recognized as official languages - Luxembourgers are generally speaking monolinguistic in Luxembourgish with their multilingualism being acquired through scholastic instruction (Fehlen, 2002; Newton, 1996). Apart from being one of the three official languages, Luxembourgish is the only national language of the Grand-Duchy; it is the main language spoken throughout the country and it is the native language for the vast majority of the Luxembourgish population. Luxembourgers use spoken French and German exclusively in the exchange with foreigners that are mostly resident in urban areas (see Kirps \& Reitz, 2001 for a detailed description of the use of languages in Luxembourg). The education system in Luxembourg is trilingual in nature. In kindergarten the language of instruction is Luxembourgish with no foreign languages being taught or used by the teachers. However, upon reaching the $1^{\text {st }}$ grade children start to learn German ( 8 hours/week) and during the second semester of the $2^{\text {nd }}$ grade children are introduced to French (3 hours/week). In the presented study children were followed longitudinally from kindergarten to second grade in order to explore whether the magnitude of a potential bilingual effect might change with development and foreign language instruction. Children completed multiple measures of working memory and language in Luxembourgish that are widely used in research with children and that have been found to provide reliable and valid measures of cognitive ability in Luxembourgish school children (Engel, 2009; Engel de Abreu, Conway, \& Gathercole, 2010).

Recent neuropsychological evidence has demonstrated use-dependent changes in brain structure (Gaser \& Schlaug, 2003; Mechelli et al., 2004), raising the possibility that a bilingual effect might be larger in older ages because of the prolonged exposure to a second language. Alternatively, the performance difference might be more pronounced in younger children. This hypothesis is based on the proposal that top down influences of linguistic knowledge on working memory performance increase with development. Assessments of verbal working memory might thus be a reflection of less pure indices of underlying working memory skills in older children when compared to younger children (Jarrold, Baddeley, Hewes, Leeke, \& Phillips, 2004) which could then mask the potential bilingual advantage in children of an older age. 


\section{Method}

\section{Participants}

In total the data from 44 children recruited from public schools from 11 villages in the Grand-Duchy of Luxembourg was analyzed. For each child a background questionnaire was obtained from the main caregiver providing detailed information on the demographic characteristics of the family, the language use in the home, as well as the parents' native and foreign language knowledge.

When first tested, children had a mean chronological age of 6 years; 4 month $(S D=2.88)$ with a range of 5 years; 9 month to 6 years; 8 month. All children scored between the $50^{\text {th }}$ and the $95^{\text {th }}$ percentile on the Raven Progressive Colored Matrices test of nonverbal reasoning (Raven, Court, \& Raven, 1986). The group consisted of 28 girls and 16 boys. Ethnic representation of the sample was $100 \%$ Caucasian. The socioeconomic status of all participants was middle to upper middle class: On average parents had completed 13.32 years of schooling $(S D=2.45$, Min $=6$, $\operatorname{Max}=16$, Median $=$ 13) and each household possessed approximately 237 books. The average number of children in each family, including the subject participating in the study, ranged from 1 to 5 with a mean of 2.4 children per family. None of the children presented severe learning difficulties or frank neurological deficits. The totality of the participants were born in Luxembourg and had completed their first year of preschool in monolingual Luxembourgish schools.

Children were selected from a larger sample of 122 multilingual Luxembourgish children. From the original sample only children that met the inclusion criteria, as outlined below, were retained for the final analyses. Participants were divided into two groups of 22 Luxembourgish monolinguals and 22 simultaneous bilinguals. Group membership was based on the parental language background questionnaire. The groups were matched on age $[t(42)=.15, p=.88, d=.05]$, sex [14 girls and 8 boys in each group], and socioeconomic status based on parental education $[t(42)=1.50, p=$ $.14, d=.45]$. Given the complexity of matching bilinguals and monolinguals on language level, children were not matched on verbal abilities; verbal skills in Luxembourgish were, however, explored in detail and used in the analyses as covariates in order to investigate the effect of language level differences.

The Bilingual group (BL; $\mathrm{N}=22$ ) consisted of children that were exposed from birth to two languages with one parent speaking Luxembourgish as the native language and the other parent speaking another first language to the child (3 French, 2 Spanish, 7 German,
4 Dutch, 3 Portuguese, 1 Czech, 2 Italian) ${ }^{1}$. All of the children started to speak Luxembourgish and their respective other native language before the age of 3 . Parents of 16 children indicated that their child learned to speak in Luxembourgish, whereas 6 children learned to speak in 2 languages. Although parents reported that children were exposed to a foreign language since birth and on a regular basis, the dominant language for all children was Luxembourgish. All the foreign speaking parents also mastered the Luxembourgish language and indicated speaking a mixture of languages in the family environment. Parents reported that their children communicated with their friends exclusively in Luxembourgish.

The Monolingual group (ML; $\mathrm{N}=22$ ) was recruited from the same classrooms as the bilinguals. All parents in this group were monolingual Luxembourgish speakers and indicated speaking Luxembourgish to their children $100 \%$ of the time. No language other than Luxembourgish was spoken within the household or within the wider family. Exposure to other languages (e.g. TV) was kept to a minimum. All of the parents read to their children in Luxembourgish. Exposure to German began at the age of 7 via scholastic instruction. When first tested in kindergarten children in the monolingual group had thus no exposure or very limited exposure to any other language. Luxembourgish was the only language that the children used with their friends or in their social environment.

\section{Procedure}

The tests were administered in Luxembourgish as part of a larger assessment battery exploring the effects of working memory on learning in young multilingual children (Engel, 2009). Each child was tested individually in a quiet area of the school by the author. Test design and adaptation followed the same principles underlying the establishment of the English originals (for further details on test translation and adaptation see Engel de Abreu et al., 2010). The digital material was presented to all children at a comfortable listening level with external speakers. Raw scores were used as dependent variables as no data was available regarding measures of standardized norms in a population of Luxembourgish children.

The children were tested on three measurement occasions within a three-year time period. The first wave of data was collected at the end of kindergarten before the start of formal instruction in reading and foreign languages had begun. The following two testing sessions took place exactly one and two years later. The second

1. In the bilingual group 10 children had French or German speaking parents (one of the official languages of the GrandDuchy). These children performed similarly to the rest of the bilingual children and differed in the same way from the monolingual group as the remaining bilingual children. 
wave of data was gathered in $1^{\text {st }}$ grade after children had learned German for approximately 9 months. The final wave of data was collected when children were in the $2^{\text {nd }}$ grade and had learned French for approximately 5 months.

The totality of the test material used for the three study waves are presented below. Tasks that form part of published test batteries are described in less detail.

\section{Tasks}

Fluid intelligence was assessed with the Raven Colored Progressive Matrices Test (Raven et al., 1986) in which a geometrical pattern has to be completed by choosing the missing piece among 6 possible drawings. The number of correctly completed trials served as the dependent variable with a total maximum score of 36 . Reliability coefficients ranged from .67 to .74 across the three testing waves.

Complex span tasks. The counting recall task and the backwards digit recall task from the Luxembourgish adapted versions of the Automated Working Memory Assessment (AWMA, Alloway, 2007) were administered. For both measures the amount of items to be remembered increases progressively over successive blocks and the number of correctly recalled trials served as the dependent variables in each case. In the Counting Recall task the subject has to count and memorize the number of circles in pictures containing both circles and triangles. At the end of each trial the subject has to recall how many circles he/she counted in each picture in the right order. Reliability coefficients ranged from .81 to .89 and the possible maximum score on the test was 42. In the Backward Digit Recall test the subject is required to repeat sequences of spoken digits in the reverse order. Reliability coefficients ranged from .80 to .85 and the possible maximum score on the test was 36 .

Simple span tasks. The Digit Recall task from the Luxembourgish AWMA (Alloway, 2007) was administered. In this test the subject is presented with sequences of spoken digits and has to immediately repeat them in the correct order. List lengths increase across blocks and the number of correctly recalled lists served as the dependent variable with a maximum score of 54 . Reliability coefficients ranged from .84 to .91 . Children also completed the Luxembourgish Nonword Repetition Task (LuNRep, Engel, 2009). In this task the subject hears unfamiliar phonological word forms (that are conform to the phonotactic properties of Luxembourgish) and has to immediately repeat them. The test contains 50 nonwords ranging in lengths from 1 to 5 syllables. The nonwords are auditory presented and responses are recorded for later analyses. The number of correctly repeated nonwords was used as the dependent variable with a total maximum score of 50 . Internal consistency coefficients of the measure ranged from .79 to .83 and interrater reliability based on Cohen's Kappa ranged from .72 to .82 .

Expressive vocabulary was assessed using the Expressive One Word Picture Vocabulary Test (EOWPVT, Brownell, 2000). In this test the subject is presented with illustrations depicting objects, actions, or concepts and is asked to name each illustration. For all children test administration started at item 1 and stopped after 8 consecutive errors. The dependent variable used for the analysis was the total number of correct responses. Reliability coefficients ranged from .85 to .91 .

Syntax. Children completed a Luxembourgish version of the Test for Reception of Grammar (TROG-2, Bishop, 2003) in which they hear a sentence and have to identify a target picture out of a choice of four. Only half of the test items were administered and no starting or stopping criterion was applied. The number of correctly identified pictures was used as the dependent variable with a possible maximum score of 40 . Internal consistency coefficients of the measure ranged from .47 to .86

\section{Results}

Skew and kurtosis for all the variables met the criteria for univariate normality (Kline, 2005). With an equal sample size of 22 cases in each group, multivariate normality of the sampling distribution of means should be assured (Mardia, 1971). No univariate outliers (values more than $3 S D$ above or below the group mean) or multivariate outliers (Mahalanobis distance $D^{2} ; p<$ .00) were detected.

Descriptive statistics for all principal measures according to group and study wave are presented in Table 1 . None of the measures manifested floor or ceiling effects: all means were at least $1 S D$ from the maximum and minimum scores. A series of two-way, mixed analysis of variance (ANOVA's) were conducted with language group as between-subject factor and study wave as within-subject factor. Significance tests of the main effect of language group together with effect sizes $\left(n_{p}^{2}\right)$ for each comparison are reported in Table 1 . An $n_{p}{ }^{2}$ of .13, .05, or .02 corresponds to a large, medium, or small effect size respectively. All the analyses were conducted twice, once using the raw data and once using z-score transformations. As the results of these analyses did not differ appreciably only the analysis based on the raw scores are presented here.

As anticipated, the main effect of the study wave was significant for all the variables with $n_{p}{ }^{2}$, s ranging between .45 and .73 . Most relevant for the present study are (a) the results on the interaction effects and (b) the main effects of language group comparing performance of the ML and the BL groups. 
TABLE 1 - Descriptive Statistics and Significance Tests According to Language Group and Study Wave

\begin{tabular}{|c|c|c|c|c|c|c|c|c|c|c|c|c|c|c|c|c|}
\hline \multirow[b]{2}{*}{ Measures } & \multirow[t]{2}{*}{ Max. } & \multicolumn{2}{|c|}{ Kindergarten } & \multicolumn{4}{|c|}{ First grade } & \multicolumn{3}{|c|}{ Second grade } & \multicolumn{2}{|c|}{ ANOVA } & \multicolumn{2}{|c|}{ Age*Group } & \multicolumn{2}{|c|}{ ANCOVA } \\
\hline & & Mean & $\mathrm{SD}$ & Range & Mean & $\mathrm{SD}$ & Range & Mean & $\mathrm{SD}$ & Range & $\mathrm{F}^{*}$ & $\mathrm{n}_{\mathrm{p}}^{2}$ & $\mathrm{~F}$ & $\mathrm{n}_{\mathrm{p}}^{2}$ & $\mathrm{~F}^{*}$ & $\mathrm{n}_{\mathrm{p}}^{2}$ \\
\hline Age (in month) & -- & & & & & & & & & & & & & & & \\
\hline ML & & 75.59 & 2.81 & $70-79$ & 87.32 & 3.09 & $80-91$ & 99.32 & 3.09 & $92-103$ & .03 & .00 & .04 & .00 & -- & \\
\hline BL & & 75.73 & 3.03 & $69-80$ & 87.50 & 3.10 & $81-92$ & 99.50 & 3.10 & $93-104$ & & & & & & \\
\hline Raven & 36 & & & & & & & & & & 1.69 & .04 & 1.38 & .03 & .19 & .01 \\
\hline ML & & 19.36 & 2.85 & $13-25$ & 24.23 & 3.43 & $17-31$ & 25.59 & 3.08 & $21-32$ & & & & & & \\
\hline $\mathrm{BL}$ & & 18.45 & 3.51 & $13-25$ & 22.41 & 2.82 & $17-27$ & 25.41 & 2.89 & $20-31$ & & & & & & \\
\hline Counting recall & 42 & & & & & & & & & & .00 & .00 & .15 & .00 & .12 & .00 \\
\hline ML & & 10.23 & 3.05 & $6-17$ & 14.64 & 3.76 & $8-21$ & 18.04 & 3.21 & $12-25$ & & & & & & \\
\hline BL & & 10.45 & 3.36 & $6-19$ & 14.32 & 2.27 & $11-20$ & 18.09 & 3.83 & $12-25$ & & & & & & \\
\hline $\begin{array}{l}\text { Back. digit } \\
\text { recall }\end{array}$ & 36 & & & & & & & & & & .34 & .01 & 1.25 & .03 & .17 & .00 \\
\hline ML & & 6.45 & 2.02 & $2-11$ & 9.04 & 2.59 & $5-14$ & 11.64 & 2.85 & $6-17$ & & & & & & \\
\hline $\mathrm{BL}$ & & 5.64 & 2.59 & $0-12$ & 9.50 & 2.28 & $6-12$ & 10.95 & 3.09 & $6-19$ & & & & & & \\
\hline Digit recall & 54 & & & & & & & & & & 1.41 & .03 & .23 & .00 & .51 & .01 \\
\hline ML & & 21.68 & 2.95 & $14-25$ & 23.54 & 3.35 & $18-32$ & 25.18 & 2.97 & $19-30$ & & & & & & \\
\hline $\mathrm{BL}$ & & 20.82 & 3.53 & $14-28$ & 22.59 & 3.71 & $17-32$ & 23.81 & 3.33 & $18-32$ & & & & & & \\
\hline LuNRep & 50 & & & & & & & & & & 5.21 & .11 & .32 & .00 & 1.69 & .04 \\
\hline ML & & 37.27 & 6.49 & $19-46$ & 41.09 & 3.22 & $34-47$ & 40.41 & 4.48 & $28-49$ & & & & & & \\
\hline BL & & 34.59 & 4.93 & $21-42$ & 37.59 & 4.73 & $27-44$ & 37.59 & 4.60 & $28-45$ & & & & & & \\
\hline EOWPVT & -- & & & & & & & & & & 12.38 & .23 & 1.43 & .03 & -- & -- \\
\hline ML & & 63.50 & 11.34 & $45-80$ & 73.64 & 7.78 & $60-88$ & 78.00 & 8.09 & $60-91$ & & & & & & \\
\hline $\mathrm{BL}$ & & 53.50 & 10.79 & $35-74$ & 64.45 & 7.20 & $52-77$ & 70.91 & 7.42 & $55-82$ & & & & & & \\
\hline TROG & 40 & & & & & & & & & & 4.38 & .10 & 3.03 & .07 & .59 & .01 \\
\hline ML & & 29.45 & 4.68 & $20-37$ & 32.04 & 2.13 & $29-37$ & 34.59 & 2.34 & $29-39$ & & & & & & \\
\hline $\mathrm{BL}$ & & 26.14 & 5.04 & $16-34$ & 31.14 & 2.69 & $27-36$ & 33.54 & 2.94 & $26-38$ & & & & & & \\
\hline
\end{tabular}

Note. Max: Maximum possible score; ML: monolingual; BL: bilingual; LuNRep: Luxembourgish Nonword Repetition; EOWPVT: Expressive One Word Picture Vocabulary Test; TROG: Test for Reception of Grammar; ${ }^{*}$ main effect of language group; in boldface $p<.05$.

The analyses showed that the interaction effects of study wave with language group were non-significant; effect sizes were small with $n_{p}{ }^{2}$ 's ranging between .00 and .03 for the working memory measures, an $n_{p}{ }^{2}$ of .03 for the Raven, and $n_{p}{ }^{2}$ s of .03 and .07 for the EOWPVT and the TROG-2 respectively.

For the main effect of language group, the data showed that groups did not differ significantly in performance on the Raven, the complex span tasks, or on the digit recall measure $\left(n_{p}{ }^{2}\right.$ ranging from .00 to .04$)$. Notably, a significant group effect emerged on nonword repetition $\left[F(1,42)=5.21, p=.03, n_{p}^{2}=.11\right]$ with monolinguals manifesting significantly higher scores. Furthermore, significant group differences were observed for expressive vocabulary and for syntax [EOWPVT: $F(1,42)=12.38, p=.00, n_{p}{ }^{2}=.23$; TROG: $\left.F(1,42)=12.38, p=.04, n_{p}^{2}=.10\right]$. As for nonword repetition, the ML group outperformed the $\mathrm{BL}$ group on both language measures.
In a last set of analyses, expressive vocabulary was included as a covariate in a series of analysis of covariance (ANCOVA's). The major divergence to the preceding results was that group differences on nonword repetition and on the TROG-2 dropped to a nonsignificant level. Effect sizes were small with an $n_{p}{ }^{2}$ of .04 for nonword repetition and an $n_{p}{ }^{2}$ of .01 for the TROG-2.

\section{Discussion}

This study explored whether simultaneous bilingual children exhibit an advantage in working memory performance when compared to their monolingual peers and how this effect might develop over time. Given previous research supporting increased task performance of bilinguals in contrast to monolinguals on measures of cognitive control (Bialystok et al., 2008; Bialystok et al., 2006; Bialystok \& Martin, 2004; 
Carlson \& Meltzoff, 2008; Martin-Rhee \& Bialystok, 2008), it was expected that a similar bilingual effect might emerge on assessments of working memory. The results of this study do not provide support for this prediction and are in line with other research findings suggesting that bilingual experience does not seem to convey any advantage in working memory abilities (Bajo et al., 2000; Bialystok et al., 2008; Namazi \& Thordardottir, 2010).

The data clearly showed that the monolinguals performed significantly better than the bilingual group on the language measures in the domain of vocabulary and syntax. This finding is consistent with other studies suggesting that, in bilinguals, both languages are active and interact during speech production which might have the negative effect of reducing the efficiency with which words from either one of the languages can be retrieved (Bialystok et al., 2006; Costa et al., 2006; Jared \& Kroll, 2001). Moreover, living with several languages on a daily basis reduces the frequency of exposure to a particular language which could further impact bilinguals performance on linguistic tasks (Gollan, Fennema-Notestine, Montoya, \& Jernigan, 2007; Grosjean, 2010). Finally, it has been argued that bilinguals' lexical knowledge is distributed across all their languages - it is therefore unsurprising that bilinguals lacked behind their monolingual peers in the present context as only one of their two languages was assessed which might have failed to cover the full range of their linguistic proficiency (Namazi \& Thordardottir, 2010; Thordardottir, 2005; Thordardottir et al., 2006).

Furthermore, the study showed that on the complex working memory span tasks and on the digit recall measure, bilingual and monolingual children performed equally well. Notably, the non-significant effect of language group could not be accounted for by the reduced verbal abilities of the bilingual speakers. In addition, there is no evidence in the data to suggest that a bilingual effect emerges across the years potentially via prolonged exposure to a second language.

One possible explanation for the absence of a bilingual effect is that the cognitive control processes underlying performance on measures of working memory and fluid intelligence are different to the type of control involved in resolving conflict between competing lexical responses in the bilingual mind. Indeed, cognitive control is a multifaceted construct that encompasses a range of processes including response inhibition, focused attention, updating, and switching (Miller $\&$ Cohen, 2001, Miyake et al., 2000). Bilingual experience might have specific effects on some of these functions but not on others. This hypothesis is in line with empirical evidence showing that bilingualism selectively affects inhibitory suppression and switching but not response inhibition or sustained attention (Bi- alystok et al., 2008; Bialystok et al., 2006; Carlson \& Meltzoff, 2008). Working memory in contrast has been more consistently linked to updating and does not seem to bear close links with inhibition or switching (Miyake et al., 2000; St Clair-Thompson \& Gathercole, 2006). Another possibility is that simultaneous bilinguals are switching between languages in a highly automatic manner and might not rely on cognitive control mechanisms when using several languages at the age of six (Namazi \& Thordardottir, 2010). Further studies are needed to explore whether sequential bilinguals who acquire their second language at a later age manifest a working memory advantage.

An interesting aspect of the data was the bilinguals' reduced performance on nonword repetition in contrast to their monolingual peers. Importantly, the effect disappeared once lexical knowledge was taken into account. This finding is consistent with previous evidence suggesting that nonword repetition is not a purely non-lexical task but instead might rely on long-term lexical and sublexical knowledge that supports the reconstruction of degrading traces in working memory (Archibald, 2008; Gathercole, Frankish, Pickering, \& Peaker, 1999; Snowling, Chiat, \& Hulme, 1991; Kohnert, Windsor, \& Yim, 2006).

The major strengths of the present study were that, as opposed to previous studies (that mainly focused on children with English and/or French as L1 or L2), bilingual and monolingual children were explored in another linguistic context; participants were matched on socioeconomic status; the study adopted a longitudinal design; and a range of measures of working memory were explored. One limitation of the study was that group sizes were relatively small, therefore statistical power may not have been sufficient enough to provide sensitivity to small differences.. It is, however, important to point out that the sample size was large enough to obtain age effects and that scores on the working memory measures were numerically higher for monolinguals than for bilinguals (rather than the opposite as predicted) raising confidence in the findings.

The present results add to the discussion on the effects of bilingualism on cognitive task performance. Although a growing body of evidence has accumulated proposing that bilingualism positively affects some processes of cognitive control, not many studies have focused on exploring the relationship between bilingualism and working memory. This study suggests that early childhood bilingualism has little impact on the development of working memory abilities. It has been argued that performance on working memory tasks is driven by the operation of multiple domain-general cognitive mechanisms: Controlled attention, updating, conflict monitoring, and interference suppression have all been suggested to underpin performance on various 
measures of working memory (see Conway, Getz, Macnamara, \& Engel de Abreu, in press, for a review). According to this multi-mechanism view of working memory it is therefore conceivable that bilingualism might differentially affect different working memory tasks. Further research is needed to explore this hypothesis and to better specify the various mechanisms underpinning performance on different working memory measures.

\section{Acknowledgements}

This project was funded by the Economic and Social Research Council (ESRC) of Great Britain and the National Research Fund (FNR) of the Grand-Duchy of Luxembourg. The study is part of a longitudinal research project investigating links between working memory and learning in childhood. The author wishes to thank the schools, teachers, and children who participated in this study, as well as Prof. Susan Gathercole, Prof. Romain Martin, and Ms Christiane Bourg for helpful comments and advice on study and task design.

Correspondence concerning this article should be addressed to Pascale M. J. Engel de Abreu, EMACS Research Unit, University of Luxembourg, L-7201 Walferdange, G.D. de Luxembourg. Email: Pascale.Engel@uni.lu

\section{References}

Alloway, T. P. (2007). Automated working memory assessment. London: Pearson Assessment.

Archibald, L. M. D. (2008). The promise of nonword repetition as a clinical tool. Canadian Journal of Speech Language Pathology and Audiology, 32, 21-28.

Baddeley, A. D. (2000). The episodic buffer: A new component of working memory? Trends in Cognitive Sciences, 4(11), 417-423.

Baddeley, A. D., Gathercole, S. E., \& Papagno, C. (1998). The phonological loop as a language learning device. Psychological Review, 105(1), 158-173.

Baddeley, A. D., \& Hitch, G. J. (1974). Working memory. In B. G. (Ed.), The psychology of learning and motivation (Vol. 8, pp. 47-90). New York Academic Press.

Bajo, M. T., Padilla, F., \& Padilla, P. (2000). Comprehension processes in simultaneous interpreting. In A. Chesterman, N. Gallardo San Salvador \& Y. Gambier (Eds.), Translation in Context (pp. 127-142). Amsterdam: Benjamins.

Bialystok, E. (1999). Cognitive complexity and attentional control in the bilingual mind. Child Development, 70(3), 636-644.

Bialystok, E. (2001). Bilingualism in development: Language, literacy, and cognition. Cambridge: Cambridge University Press.

Bialystok, E., Craik, F. I. M., Klein, R., \& Viswanathan, M. (2004). Bilingualism, aging, and cognitive control: Evidence from the Simon task. Psychology and Aging, 19, 290-303.
Bialystok, E., Craik, F. I. M., \& Luk, G. (2008). Cognitive control and lexical access in younger and older bilinguals. Journal of Experimental Psychology: Learning Memory and Cognition, 34(4), 859-873.

Bialystok, E., Craik, F. I. M., \& Ryan, J. (2006). Executive control in a modified antisaccade task: Effects of aging and bilingualism. Journal of Experimental PsychologyLearning Memory and Cognition, 32(6), 1341-1354.

Bialystok, E., \& Martin, M. M. (2004). Attention and inhibition in bilingual children: evidence from the dimensional change card sort task. Developmental Science, 7(3), 325339.

Bishop, D. V. M. (2003). Test for reception of grammarVersion 2. London: Psychological Corporation.

Brownell, R. (2000). Expressive one word picture vocabulary test. London: Psychological Corporation.

Bunting, M. F. (2006). Proactive interference and item similarity in working memory. Journal of Experimental Psychology: Learning, Memory, and Cognition, 32, 183-196.

Carlson, S. M., \& Meltzoff, A. N. (2008). Bilingual experience and executive functioning in young children. Developmental Science, 11(2), 282-298.

Conway, A. R. A., Cowan, N., Bunting, M. F., Therriault, D. J., \& Minkoff, S. R. B. (2002). A latent variable analysis of working memory capacity, short-term memory capacity, processing speed, and general fluid intelligence. Intelligence, 30(2), 163-183.

Conway, A. R. A., Macnamara, B., Getz, S., \& Engel de Abreu, P. M. J. (in press). Working memory and fluid intelligence: A multi-mechanism view. In. R. Sternberg \& S. Barry Kaufman (Eds). Cambridge Handbook of Intelligence. New York: Cambridge University Press.

Costa, A., Roelstraete, B., \& Hartsuiker, R. (2006). The lexical bias effect in bilingual speech production: Evidence for feedback between lexical and sublexical levels across languages. Psychonomic Bulletin \& Review, 13, 612-617.

Cowan, N., Elliott, E. M., Saults, J. S., Morey, C. C., Mattox, S., Hismjatullina, A., et al. (2005). On the capacity of attention: Its estimation and its role in working memory and cognitive aptitudes. Cognitive Psychology, 51(1), 42-100.

Engel, P. M. J. (2009). Working memory and learning: A 3year longitudinal study of children growing up in a multilingual environment. University of York, York.

Engel de Abreu, P. M. J., Conway, A. R. A. \& Gathercole, S. E. (2010). Working memory and fluid intelligence in young children. Intelligence. 38(6). 552-561.

Engle, R. W. (2010). Role of working memory capacity in cognitive control. Current Anthropology, 51, S1.

Engle, R. W., Tuholski, S. W., Laughlin, J. E., \& Conway, A. R. A. (1999). Working memory, short-term memory, and general fluid intelligence: A latent-variable approach. Journal of Experimental Psychology-General, 128(3), 309-331.

Espy, K. A., \& Bull, R (2005). Inhibitory processes in young children and individual variation in short-term memory. Developmental Neuropsychology, 28, 669-688.

Fehlen, F. (2002). Luxembourg, a multilingual society at the Romance/Germanic language border. Journal of Multilingual and Multicultural Development, 23(1\&2), 80-97.

Gathercole, S. E., Frankish, C. R., Pickering, S. J., \& Peaker, S. (1999). Phonotactic influences on short term memory. 
Journal of Experimental Psychology: Learning, Memory and Cognition, 25(1), 84-95.

Grosjean, F. (2010). Bilingual: Life and Reality. Cambridge, Mass: Harvard University Press.

Gaser, C., \& Schlaug, G. (2003). Brain structures differ between musicians and non-musicians. Journal of Neuroscience, 23, 9240-9245.

Gollan, T. H., Fennema-Notestine, C., Montoya, R. I., \& Jernigan, T. L. (2007). The bilingual effect on Boston Naming Test performance. Journal of the International Neuropsychological Society, 13, 197-208.

Jaeggi, S. M., Buschkuehl, M., Jonides, J., EF Perrig, W. J. (2008). Improving fluid intelligence with training on working memory. Proceedings of the National Academy of Sciences of the United States of America, 105(19), 6829-6833.

Jared, D., \& Kroll, J. (2001). Do bilinguals activate phonological representations in one or both of their languages when naming words? Journal of Memory and Language, 44, 2-31.

Jarrold, C., Baddeley, A. D., Hewes, A. K., Leeke, T. C., \& Phillips, C. E. (2004). What links verbal short-term memory performance and vocabulary level? Evidence of changing relationships among individuals with learning disability. Journal of Memory and Language, 50(2), 134148.

Kane, M. J., \& Engle, R. W. (2000). Working memory capacity, proactive interference, and divided attention: Limits on long-term memory retrieval. Journal of Experimental Psychology: Learning, Memory, and Cognition, 26, 333358.

Kirps, J., \& Reitz, J. (2001). National report: Grand-Duchy of Luxembourg. Strasbourg: Council of Europe.

Kline, R. B. (2005). Principles and practice of structural equational modelling (second ed.). New York: The Guilford Press.

Klingberg, T., Forssberg, H., \& Westerberg, H. (2002). Training of working memory in children with ADHD. Journal of Clinical and Experimental Psychology, 24, 781-791.

Kohnert, K., Windsor, J., \& Yim, D. (2006). Do language based processing tasks separate children with language impairment from typical bilinguals? Learning Disabilities Research \& Practice, 21, 19-29.

Majerus, S., Poncelet, M., Greffe, C., \& van der Linden, M. (2006). Relations between vocabulary development and verbal short-term memory: The relative importance of short-term memory for serial order and item information. Journal of Experimental Child Psychology, 93(2), 95-119.

Mardia, K. V. (1971). The effect of nonnormality on some multivariate tests and robustness to nonnormality in the linear model. Biometrika, 58, 105-121.

Martin-Rhee, M. M., \& Bialystok, E. (2008). The development of two types of inhibitory control in monolingual and bilingual children. Bilingualism-Language and Cognition, 11(1), 81-93.

Masoura, E. V., \& Gathercole, S. E. (2005). Contrasting contributions of phonological short-term memory and long-term knowledge to vocabulary learning in a foreign language. Memory, 13(3-4), 422-429.
Mechelli, A., Crinion, J. T., Noppeney, U., O’Doherty, J., Ashburner, J., Frackowiak, R. S., et al. (2004). Structural plasticity in the bilingual brain. Nature, 431, 757.

Miller E. K. \& Cohen, J. D. (2001). An integrative theory of prefrontal cortex function. Annual Review of Neuroscience. 24, 167-202.

Miyake, A., Friedman, N. P., Emerson, M. J., Witzki, A. H., Howerter, A., \& Wager, T. D. (2000). The unity and diversity of executive functions and their contributions to complex "frontal lobe" tasks: A latent variable analysis. Cognitive Psychology, 41(1), 49-100.

Namazi, M., \& Thordardottir, E. (2010). A working memory, not bilingual advantage, in controlled attention. International Journal of Bilingual Education and Bilingualism, 13 (5). 597-616.

Newton, G. (1996). Luxembourg and Lëtzebuergesch: Language and communication at the crossroad of Europe. Oxford: Clarendon Press.

Pearson, B., Fernández, S., \& Oller, D. K. (1995). Lexical development in bilingual infants and toddlers: Comparison to monolingual norms. Language Learning, 43, 93120.

Raven, J. C., Court, J. H., \& Raven, J. (1986). Colored progressive matrices. London: H. K. Lewis.

Service, E. (2006). Phonological networks and new word learning. Applied Psycholinguistics, 27(4), 581-584.

Snowling, M., Chiat, S., \& Hulme, C. (1991). Words, nonwords, and phonological processes - Some comments on Gathercole, Willis, Emslie, and Baddeley. Applied Psycholinguistics, 12(3), 369-373.

St Clair-Thompson, H. L., \& Gathercole, S. E. (2006). Executive functions and achievements in school: Shifting, updating, inhibition, and working memory. Quarterly Journal of Experimental Psychology, 59(4), 745-759.

Thordardottir, E. (2005). Early lexical and syntactic development in Quebec French and English: Implications for cross-linguistic and bilingual assessment. International Journal of Language and Communication Disorders, 40, 243-278

Thordardottir, E., Rothenberg, A., Rivard, M.-E., \& Naves, R. (2006). Bilingual assessment: Can overall proficiency be estimated from separate measurement of two languages? Journal of Multilingual Communication Disorders, 4 (1),1-21.

Unsworth, N., \& Engle, R. W. (2007). On the division of short-term and working memory: An examination of simple and complex spans and their relation to higher order abilities. Psychological Bulletin, 133, 1038-1066.

Ursino, M., Cuppini, C., \& Magosso, E. (2010). A semantic model to study neural organization of language in bilingualism. Computational Intelligence and Neuroscience, 2010:350269.

Van Hell, J. G., \& Dijkstra, T. (2002). Foreign language knowledge can influence native language performance in exclusively native contexts. Psychonomic Bulletin \& Review, 9, 780-789. 